\title{
Sistem Pendukung Keputusan Pemberian Kredit Sepeda Motor Pada PT Adira Finance Medan Menggunakan Metode SAW
}

\author{
Mikhael Armando Manullang ${ }^{1 *}$, Hasanul Fahmi \\ ${ }^{1.2}$ STMIK Pelita Nusantara \\ Jl. Iskandar Muda No. 1 Medan 20154 Indonesia \\ Corresponding author's e-mail: mazkenzie345@gmail.com
}

\begin{abstract}
Abstrak - Banyak masyarakat yang ingin memiliki sepeda motor, tetapi tidak memiliki dana yang cukup untuk membeli motor secara tunai, dibutuhkan suatu cara untuk memiliki motor dengan menggunakan sistem pembayaran secara kredit. Perumusan masalah yang akan diselesaikan dalam penelitian ini adalah bagaimana merancang SPK dalam menentukan kredit sepeda motor bagi nasabah baru pada PT Adira Finance menggunakan metode SAW. Batasan masalah dalam penelitian ini aplikasi tidak menangani penanaman dana dari nasabah berupa tabungan, deposito dan lain-lain, aplikasi hanya mendukung keputusan pemberian kredit terhadap nasabah dengan kriteria-kriteria yang sudah ditentukan dan aplikasi tidak menangani penambahan kriteria-kriteria nasabah. Tujuan penelitian yaitu PT. Adira Finance dapat menentukan debitur yang layak mendapatkan kredit dan membuat SPK untuk menentukan kelayakan pemberian kredit di PT. Adira Finance. hasil perhitungan nilai V (perangkingan), V1 = Nasabah $1(0,91)$ V4 = Nasabah $4(0,91)$ V2 = Nasabah 2 $(0,63)$ V3 = Nasabah $3(0,51)$ V5 = Nasabah $5(0,31)$.
\end{abstract}

Kata kunci: SPK, metode $S A W$, kredit, ranking, bobot

Abstract - Many people who want to own a motorbike, but do not have sufficient funds to buy a motorbike in cash, require a way to own a motorbike using a credit payment system. The formulation of the problem to be resolved in this study is how to design the SPK in determining motorcycle loans for new customers at PT Adira Finance using the SAW method. The limitation of the problem in this research is that the application does not handle the investment of funds from customers in the form of savings, time deposits and others, the application only supports the decision to grant credit to customers with predetermined criteria and the application does not handle the addition of customer criteria. The research objective is PT. Adira Finance can determine creditworthy debtors and prepare SPK to determine creditworthiness at PT. Adira Finance. From the results of the calculation of the V value above, a ranking is made: V1 = Customer 1 (0.91) V4 = Customer 4 (0.91) V2 = Customer 2 (0.63) V3 = Customer 3 (0.51) V5 = Customer 5 (0.31).

Keywords: SPK, SAW method, credit, ranking, weight

\section{Pendahuluan}

Dalam rangka meringankan beban pembayaran sepeda motor, PT. Adira Finance memberikan fasilitas pembayaran secara kredit bagi calon pembeli sepeda motor. Dealer tersebut akan memberikan kredit sesuai kriteria-kriteria yang harus dicapai oleh calon pembeli. Dengan adanya sistem kredit ini jumlah calon pembeli yang akan mengajukan kredit akann semakin bertambah, sehingga dealer dituntut harus dapat melayani konsumen dengan melakukan analisa dan membutuhkan data-data calon pembeli yang memiliki kemampuan pembayaran kredit. Dalam menentukan layak atau tidaknya pemohon kredit, acuan utama dealer adalah berdasarkan karakter pribadi pemohon yang baik atau tidaknya pemohon kredit, acuan utama dealer adalah berdasarkan karakter pribadi pemohon yang baik atau tidak berdasarkan kemampuan pemohon dalam angsuran kredit. Penentuan tersebut dibuat agar tidak menimbulkan masalah dikemudian hari. Pemberian kredit yang tidak sesuai kriteria akan menimbulkan resiko kredit macet. Pegawai dealer membutuhkan waktu yang cukup lama dalam menyeleksi dokumen calon peng kredit.

Masalah Sistem Pendukung Keputusan atau sering disebut Decision Support Sistem (DSS) adalah Sistem berbasis model yang terdiri dari prosedur- prosedur dalam pemrosesan data dan pertimbangannya untuk membantu manajer dalam mengambil keputusan [1]. Pada dasarnya DSS dirancang untuk mendukug seluruh tahap pengambilan keputusan mulai dari mengidentifikasi masalah, memilih data yang relevan, menentukan pendekatan yang digunakan dalam proses pengambilan keputusan sampai mengevaluasi pemlihan alternatif [2]. Dalam proses pengambilan keputusan untuk menghasilkan suatu alternative membutuhkn suatu metode. Ada beberapa metode yang dipakai dalam SPK dan salah satunya adalah metode Simple Additive Weighting (SAW) [3]. Konsep dasar dari metode SAW adalah mencari penjumlahan terbobot dari rating kinerja untuk setiap alternative pada semua kriteria atau atribut. Hal itu karena perangkingan dalam menentukan alternative 
terbaik pada metode SAW, didasarkan pada kriteria dan bobot yang ditentukan diawal.

Penelitian Sistem Pendukung Keputusan Pemberian Kredit Elektronik Pada PT Premium Central Indosarana Menggunakan Metode Simple Additive Weighting (SAW) menjelaskan Sistem Pendukung Keputusan (SPK) merupakan suatu sistem komputer yang dapat membantu pengguna dalam menentukan suatu keputusan mengolah suatu data mentah ataupun dokumen menjadi suatu informasi yang akurat. SPK bisa digunakan secara individu maupun kelompok [4]. Penelitian Sistem Pendukung Keputusan Pengajuan Kredit dengan Metode SAW pada KJKS AR Rahmah menjelaskan Sistem ini menggunakan metode SAW untuk kelayakan pemberian kredit, sistem memiliki dua hak akses yaitu admin mikro dan manajer [5]. Sistem ini dapat mengelola nasabah yang telah mengajukan kredit terhadap bank, mengelola nilai nasabah, mengelola kriteria nasabah, dan mengelola nilai kriteria nasabah. Penelitian sistem pendukung keputusan penerimaan kredit modal usaha pada PT.BANK BPR PMM menjelaskan Metode SAW merupakan metode Fuzzy MADM yang paling sederhana dan paling banyak digunakan. Metode ini juga metode yang paling mudah untuk diaplikasikan, karena mempunyai algoritma yang tidak terlalu rumit.Metode SAW sering juga dikenal istilah metode penjumlahan terbobot [6]. Konsep dasar metode SAW adalah mencari penjumlahan terbobot dari rating kinerja pada setiap alternatif pada semua atribut [7].

\section{Tinjauan Pustaka}

\subsection{Sistem Pendukung Keputusan}

Sistem pendukung keputusan didefinisikan sebagai sistem informasi pada level manajemen dari suatu organisasi yang mengkombinasikan data dan model analisis canggih atau peralatan data analisis untuk mendukung pengambilan yang semi terstruktur dan tidak terstruktur [8]. Sistem Pendukung Keputusan (SPK) yaitu sebuah sistem berbasis komputer yang adaptif, fleksibel dan interaktif yang digunakan untuk memecahkan masalah-masalah tidak terstruktur sehingga meningkatkan nilai keputusan yang diambil [9]. komponen-komponen dari sistem pendukung keputusan adalah Manajemen Data, mencakup database yang mengandung data yang relevan dan diatur oleh sistem yang disebut Database Management System (DBMS) dan Manajemen Model, merupakan paket perangkat lunak yang memasukkan model-model finansial, statistik, ilmu manajemen, atau model kuantitatif yang lain yang menyediakan kemampuan analisis sistem dan management software yang terkait [10].

\subsection{SAW}

Metode Simple Additive Weighting (SAW) sering juga dikenal istilah metode penjumlahan terbobot. Konsep dasar metode SAW adalah mencari penjumlahan terbobot dari rating kinerja pada setiap alternatif pada semua atribut [11]. Metode SAW membutuhkan proses normalisasi matriks keputusan (X) ke suatu skala yang dapat diperbandingkan dengan semua rating alternatif yang ada. Metode ini merupakan metode yang paling terkenal dan paling banyak digunakan dalam menghadapi situasi Multiple Attribute Decision Making (MADM). MADM itu sendiri merupakan suatu metode yang digunakan untuk mencari alternatif optimal dari sejumlah alternatif dengan kriteria tertentu. Dalam metode SAW dilakukan langkah-langkah sebagai berikut [12]:

1. Menentukan kriteria-kriteria yang akan dijadikan acuan dalam pengambilan keputusan, yaitu Ci.

2. Menentukan rating kecocokan setiap alternatif pada setiap kriteria.

3. Membuat matriks keputusan berdasarkan kriteria (Ci), kemudian melakukan normalisasi matriks berdasarkan persamaan yang disesuaikan dengan jenis atribut (atribut keuntungan ataupun atribut biaya) sehingga diperoleh matriks ternormalisasi

4. Hasil akhir diperoleh dari proses perangkingan yaitu penjumlahan dari perkalian matriks ternormalisasi $\mathrm{R}$ dengan vektor bobot sehingga diperoleh nilai terbesar yang dipilih sebagai alternatif terbaik (Ai) sebagai solusi,

5. Melakukan normalisasi

6. Nilai preferensi untuk setiap alternatif (Vi)

\section{Metode Penelitian}

Metode penelitian, sebagai berikut:

1. Analisa Masalah, sekumpulan kegiatan, aktivitas dan proses yang saling berkaitan untuk memecahkan masalah atau memecahkan komponen menjadi lebih detail dan digabungkan kembali lalu ditarik kesimpulan.

2. Pengumpulan data

Merupakan kegiatan mencari data di lapangan yang akan digunakan untuk menjawab permasalahan penelitian. Validitas instrumen pengumpulan data serta kualifikasi pengumpul data sangat diperlukan untuk memperoleh 
data yang berkualitas.

3. Analisis Data, upaya atau cara untuk mengolah data menjadi informasi sehingga karakteristik data tersebut bisa dipahami dan bermanfaat untuk solusi permasalahan.

4. Proses Metode SAW, metode penjumlahan terbobot. Konsep dasar pada metode SAW adalah mencari penjumlahan terbobot dari rating kinerja pada setiap alternatif di semua atribut.

5. Perancangan Pembangunan Sistem, desain sistem menentukan bagaimana suatu sistem akan menyelesaikan apa yang mesti diselesaikan, tahap ini menyangkut mengkonfigurasikan dari komponenkomponen perangkat lunak dan perangkat keras dari suatu sistem sehingga setelah instalasi dari sistem akan benar benar memuaskan rancang bangun yang telah ditetapkan pada akhir analisis sistem.

6. Implementasi Sistem, tahap penerapan sistem yang akan dilakukan jika sistem disetujui termasuk program yang telah dibuat pada tahap perancangan sistem agar siap untuk dioperasikan.

7. Pengujian Sistem, engujian program perangkat lunak yang lengkap dan terintegrasi. Biasanya, perangkat lunak dihubungkan dengan perangkat lunak dan perangkat keras lainnya.

\section{Hasil dan Pembahasan}

Metode SAW sering juga dikenal dengan istilah metode penjumlahan terbobot. Konsep dasar metode SAW adalah mencari penjumlahan terbobot dengan rating kinerja pada setiap alternatif pada semua atribut. Kriteriakriteria yang digunakan dalam menentukan pemberian kredit berdasarkan wawancara yang dilakukan oleh penulis kepada Credit Analyst PT. Adira Finance adalah Character (C1), bagaimana karakter pelanggan dalam hal ini identitas. Capacity (C2), kapasitas melunasi kredit dalam hal ini pekerjaan. Capital (C3), kemampuan yang dimiliki pelanggan seperti pendapatan. Collateral (C4), jaminan yang dimiliki untuk menanggung resiko kredit. Condition (C5), keuangan pelanggan dalam hal ini seperti rekening tabungan pelanggan memilikinya atau tidak. Character (C1) Benefit= 30 ; Capacity (C2) Benefit 25 ; Capital (C3) Benefit =20 ; Collateral (C4) Benefit $=15$; Condition $($ C5) Benefit $=10$.

Normalisasi Nilai R untuk menghitung nilai masing-masing kriteria :

\section{Alternatif Nasabah 1}

$\mathrm{r} 1=80: \operatorname{Max}(80 ; 60 ; 50 ; 70 ; 30)=1$

r2 $=71: \operatorname{Max}(71 ; 29 ; 43 ; 57 ; 14)=1$

r3 $=100: \operatorname{Max}(100 ; 67 ; 33 ; 100 ; 33)=1$

$\mathrm{r} 4=40: \operatorname{Max}(40 ; 80 ; 60 ; 100 ; 20)=0,4$

r5 $=100:$ Max $(100 ; 50 ; 50 ; 100 ; 50)=1$

Alternatif Nasabah 2

r6 $=60: \operatorname{Max}(80 ; 60 ; 50 ; 70 ; 30)=0,75$

r7 $=29: \operatorname{Max}(71 ; 29 ; 43 ; 57 ; 14)=0,40$

r8 = 67: Max $(100 ; 67 ; 33 ; 100 ; 33)=0,67$

r9 $=80: \operatorname{Max}(40 ; 80 ; 60 ; 100 ; 20)=0,8$

$\mathrm{r} 10=50: \operatorname{Max}(100 ; 50 ; 50 ; 100 ; 50)=0,5$

Alternatif Nasabah 5

$\mathrm{r} 21=30: \operatorname{Max}(80 ; 60 ; 50 ; 70 ; 30)=0,37$

r22 = $14: \operatorname{Max}(71 ; 29 ; 43 ; 57 ; 14)=0,19$

r23 = 33: Max $(100 ; 67 ; 33 ; 100 ; 33)=0,33$

r24 $=20: \operatorname{Max}(40 ; 80 ; 60 ; 100 ; 20)=0,2$

r25 = 50: Max $(100 ; 50 ; 50 ; 100 ; 50)=0,5$

Proses perangkingan dengan menggunakan bobot yang ada, yang telah diberikan oleh pengambil keputusan : $\mathrm{W}=\left[\begin{array}{lllll}0.3 & 0.25 & 0.2 & 0.15 & 0.1\end{array}\right]$

Hasil yang diperoleh adalah sebagai berikut :

$$
\mathrm{V} 1=(0,3)(1)+(0,25)(1)+(0,2)(1)+(0,15)(0,4)+(0,1)(1)
$$

$=0,3+0,25+0,2+0,06+0,1=0,91$

$\mathrm{V} 2=(0,3)(0,75)+(0,25)(0,40)+(0,2)(0,67)+(0,15)(0,8)+(0,1)(0,5)$

$=0,22+0,1+0,13+0,12+0,05=0,63$

V3 $=(0,3)(0,5)+(0,25)(0,60)+(0,2)(0,33)+(0,15)(0,6)+(0,1)(0,5)$

$=0,15+0,15+0,07+0,09+0,05=0,51$

$\mathrm{V} 4=(0,3)(0,87)+(0,25)(0,80)+(0,2)(1)+(0,15)(1)+(0,1)(1)$

$=0,26+0,2+0,2+0,15+0,1=0,91$

V5 $=(0,3)(0,37)+(0,25)(0,19)+(0,2)(0,33)+(0,15)(0,2)+(0,1)(0,5)$ $\mathrm{r} 13=33: \operatorname{Max}(100 ; 67 ; 33 ; 100 ; 33)=0,33$

$\mathrm{r} 14=60: \operatorname{Max}(40 ; 80 ; 60 ; 100 ; 20)=0,6$

Alternatif Nasabah 4

r16 $=70: \operatorname{Max}(80 ; 60 ; 50 ; 70 ; 30)=0,87$

$\mathrm{r} 17=57: \operatorname{Max}(71 ; 29 ; 43 ; 57 ; 14)=0,80$

$\mathrm{r} 18=100: \operatorname{Max}(100 ; 67 ; 33 ; 100 ; 33)=1$

$\mathrm{r} 19=100: \operatorname{Max}(40 ; 80 ; 60 ; 100 ; 20)=1$

$\mathrm{r} 20=100: \operatorname{Max}(100 ; 50 ; 50 ; 100 ; 50)=1$ 
$=0,11+0,05+0,07+0,03+0,05=0,31$

Dari hasil perhitungan nilai V di atas di buatlah suatu perangkingan : V1 = Nasabah $1(0,91)$

V4 = Nasabah $4(0,91)$

$\mathrm{V} 2=$ Nasabah $2(0,63)$

$\mathrm{V} 3=$ Nasabah $3(0,51)$

V5 = Nasabah $5(0,31)$

Implementasi berfungsi untuk mempersentasikan hasil program dalam penulisan skripsi yang merupakan proses penerapan metode Simple Additive Weighting yang dirancang menggunakan berbasis web dan menguji program web apakah berjalan dengan baik.

a. Form Menu Utama merupakan tampilan aplikasi setelah user berhasil login. Pada halaman utama terdapat beberapa menu yaitu nilai referensi, Kriteria, , bobot kriteria, alternatif.

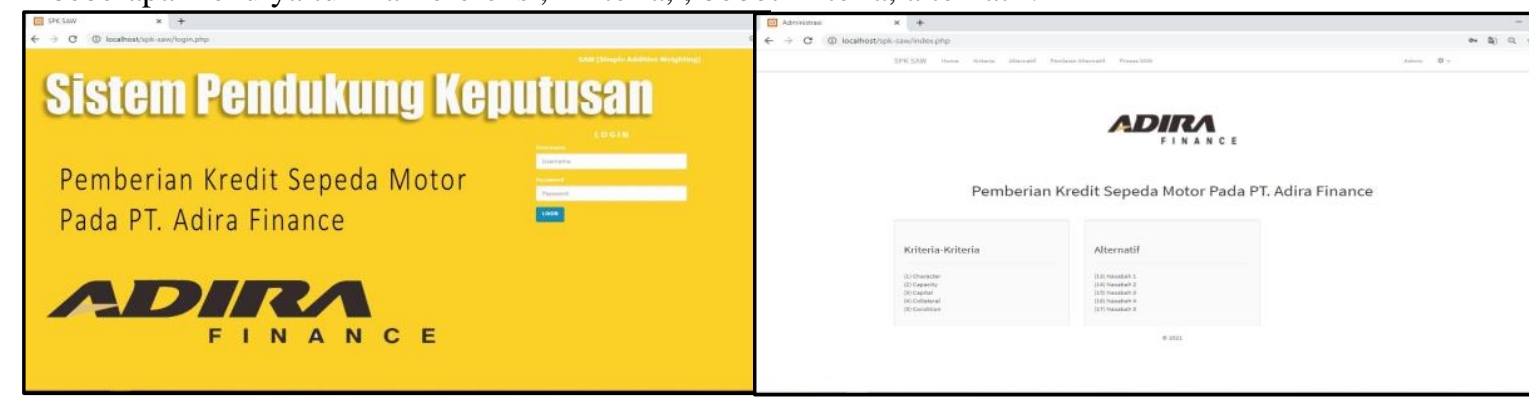

\section{Gambar 1. Menu Utama}

b. Form Halaman kriteria merupakan form untuk melakukan proses penginputan data kriteria. Pada halaman ini terdapat daftar kriteria dan ada menu tambah kriteria,cari kriteria.

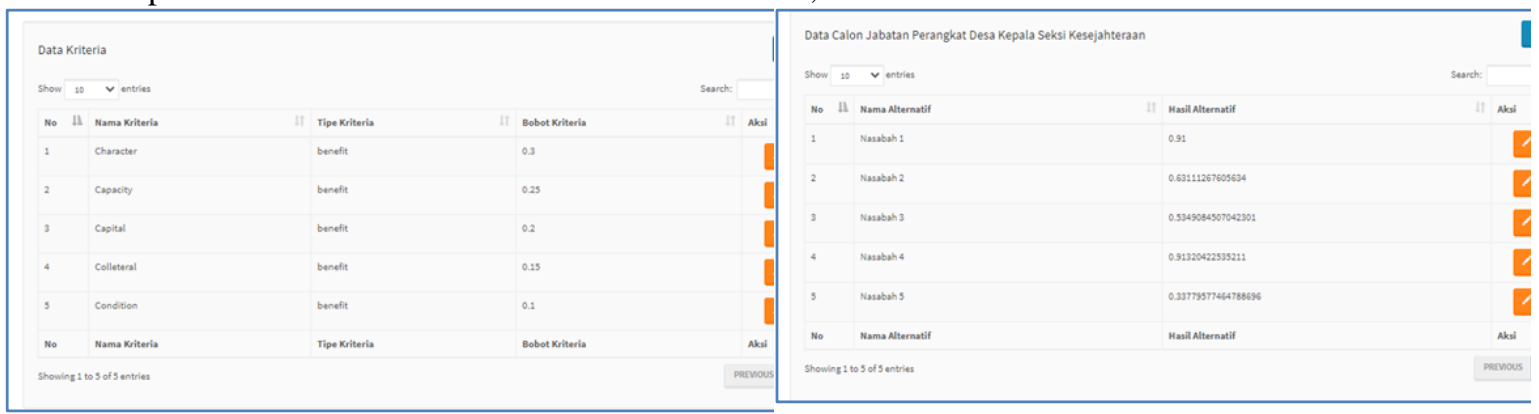

Gambar 2. Menu Kriteria 


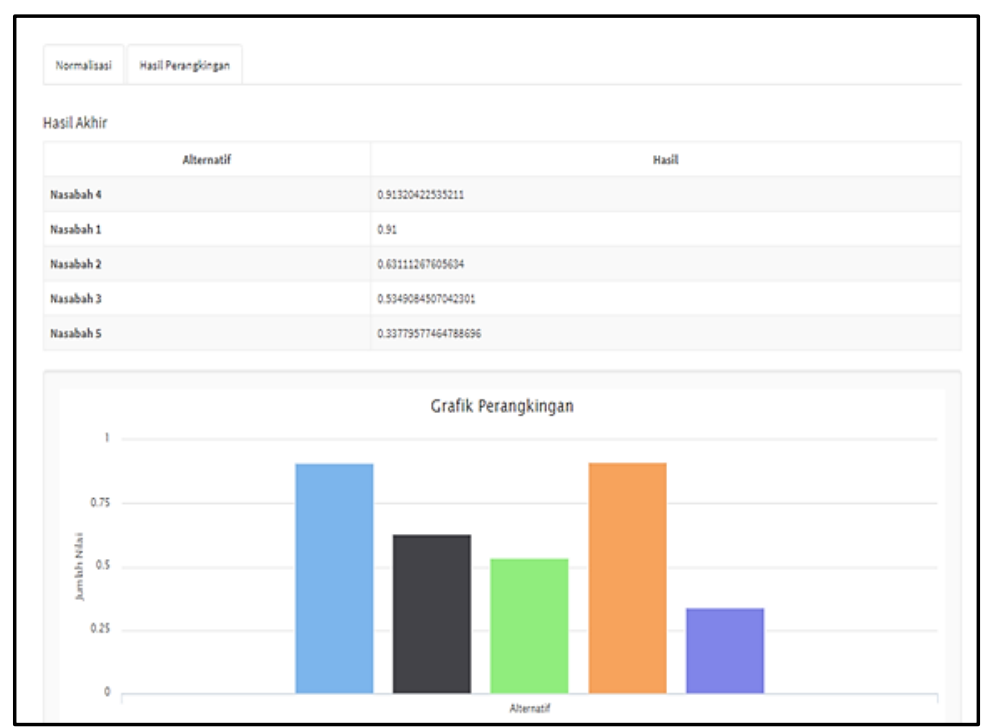

Gambar 3. Tampilan Hasil SAW

\section{Kesimpulan}

Kesimpulan dari penelitian :

1. Penggunaan Metode Simple Additive Weighting dalam penelitian ini mampu memberikan hasil keputusan dalam Sistem Pendukung Keputusan Pemberian Kredit Sepeda Motor Pada PT Adira Finance Medan.

2. Kriteria dalam penelitian ini dijelaskan lebih terperinci supaya tidak menimbulkan pertanyaan dari pihak manapun.

3. Mempermudah PT Adira Finance Medan untuk menentukan penerimaan Kredit Sepeda Motor bagi Nasabah baru dan dapat di print.

\section{Daftar Pustaka}

[1] Hasan, Patmawati. 2018. "Sistem Pendukung Keputusan Penerimaan Kredit Modal Usaha Pada Pt.Bank Bpr Pmm.” Jurnal Sistem Informasi Dan Teknologi Informasi 7(1):77-88.

[2] Tanto. 2014. "Perancangan Sistem Pendukung Keputusan Pemberian Kredit Kepemilikan Rumah (KPR) Dengan Metode Simple Additive Weighting.” Jurnal Sistem Informasi 1(1):42-44.

[3] Nurul Putri Utami, Hasanul Fahmi, and Anita Sindar. 2019. "Spk Penentuan Pemberian Pinjaman Kepada Anggota Bumdes Dengan Metode Simple Additive Weighting." SINTECH (Science and Information Technology) Journal 2(2):124-30. doi: 10.31598/sintechjournal.v2i2.317.

[4] Hulu, Damayanti, and R. Mahdalena Simanjorang. 2021. "Sistem Pendukung Keputusan Pemilihan Topik Skripsi Program Studi Teknik Informatika Menggunakan Simple Additive Weighting ( SAW )." $4(1): 64-68$.

[5] Wahyu, Istianto, Suparni Suparni, and Achmad Baroqah Pohan. 2020. "Sistem Pendukung Keputusan Pemberian Pinjaman Pada KOPWALI Tangerang Dengan Metode AHP Dan SAW." IJCIT (Indonesian Journal on Computer and Information Technology) 5(1):21-30. doi: 10.31294/ijcit.v5i1.6559.

[6] Maria, Anita, Agus Sidiq Purnomo, Program Studi Informatika, Fakultas Teknologi Informasi, Universitas Mercu, Buana Yogyakarta, Income Lain, Multiple Attribute, Decesion Making, Sistem Pendukung Keputusan, Pengajuan Kredit, and Jenis Usaha. 2019. "Sistem Pendukung Keputusan Pengajuan Kredit Menggunakan.” 100:106-14.

[7] Sinaga, Anita Sindar RM, Murni Marbun, and Arjon Samuel Sitio. 2021. "Penerapan Teknologi Informasi Penentuan Prioritas Penerima Bantuan Langsung Tunai (BLT) Desa Pagar Jati.” Jurdimas (Jurnal Pengabdian Kepada Masyarakat) Royal 4(1):65-70. doi: 10.33330/jurdimas.v4i1.681.

[8] Chaniago, Nurlisna, and Anita Sindar. 2020. "SPK Penilaian Hasil Belajar Siswa Menggunakan Metode TOPSIS." 9:41-48.

[9] Fightorini, Ervin, and Bowo Nurhadiono. 2013. "Sistem Pendukung Keputusan Pengajuan Kredit Dengan Metode Saw Pada KJKS Ar Rahmah.” Journal Udinus 1-5.

[10] Timotius, Fatma Agus Setyaningsih, and Uray Ristian. 2018. "Sistem Pendukung Keputusan 
Peminjaman Dana Kredit CU BIMA Cabang Tempunak Menggunakan Metode Simple Addictive Weighting (SAW) Berbasis Web.” Jurnal Coding 06(03):265-75.

[11] Pendukung, Sistem, Keputusan Kelayakan, Kredit Mikro, Bank Mandiri, Dengan Menggunakan, and Metode Simple. 2019. “Inti Nusa Mandiri.” 14(1):199-204.

[12] Wibowo, Ari, and Keanu Kunendra. 2018. "Sistem Pendukung Keputusan Penilaian Kelayakan Kredit Menggunakan Metode Simple Additive Weighting (SAW)." Journal of Applied Informatics and Computing 1(1):22-25. doi: 10.30871/jaic.v1i1.511. 